\title{
KEYNOTE: Transactional Analysis Psychotherapy Research: Three Methods describing a TA Group Therapy
}

\author{
C2012 Roland Johnsson TSTA Psychotherapy
}

\begin{abstract}
The overall aim of the thesis was to enhance and revive the practical understanding of the active ingredients in Transactional Analysis Psychotherapy (TA) and to define and lay down elements of TA that make it a distinct and replicable method of treatment.

The thesis includes three empirical studies of a videotaped one-year long TA Group Therapy with 10 clients. Three different key areas of Transactional Analysis have been investigated with support of three different approaches.
\end{abstract}

The first study (Johnsson, 2011 a) was a diagnostic client assessment with TA Script Analysis made as a reliability study. The second study (Johnsson, 2011 b) dealt with identification of different components in TA psychotherapy method with the use of Discourse Analysis and the third study (Johnsson \& Stenlund, 2010) investigated the Therapeutic Alliance with a psychodynamic approach, using the CCRT method (the CORE Conflictual Relationship method) by Luborsky \& Crits-Christoph $(1990,1998)$ and the Plan - Diagnosis method by Weiss \& Sampson (1986).

Study I: A script questionnaire and associated checklist developed by Ohlsson, Johnsson \& Björk (1992) was used by the author and two professional colleagues to independently assess ten clients of a year-long transactional analysis therapy group conducted by the author. Ratings based on written responses at start of therapy were compared to ratings based on videotape interviews conducted by the author six years after termination of therapy. Moderately high inter-assessor reliability was found but intra-assessor reliability was low for the independent assessors; agreement increased for script components 'primary injunction from father,' 'racket feeling', 'escape hatch', 'driver from father' and 'driver from mother'.

Study II: Operational definitions of categorisations by McNeel (1975) were developed and applied by the author and an independent assessor to complete discourse analysis of 72 hours of transactional analysis group therapy in the style of Goulding \& Goulding (1976, 1979) conducted during 1984/85. Results showed that the therapist used an average of $42 \%$ of the discourse space and that the therapy did indeed contain TA components, with the two main categories being 'Feeling Contact' and 'Contracts', and with particular use of TA techniques of 'talking to Parent projections', 'make feeling statement', 'mutual negotiation' and 'specificity/clarity'. Inter-rater reliability was $46.2 \%$ (Araujo \& Born 1985), Cohen's (1960) kappa coefficient shows a spread from slight to moderate agreement, and the Odds Ratio (Viera, 2008) is above 1.0 for most categories. One intervention, "mutual negotiation", with moderate reliability could be identified as "TA typical".

Study III: The study describes an investigation of the significance of the affective dimension of the therapeutic alliance (Bordin 1979), in a psychodynamic form of transactional analysis therapy after the style of "Redecision therapy" (Goulding \& Goulding, 1979). We explored the client's pattern of affective relationships by use of CCRT by Luborsky \& Crits-Christoph $(1990,1998)$ and examined how the therapist responds to the client's affective messages ("tests") by use of the Plan-Diagnosis method (Weiss \& Sampson, 1986). We found that "emotional" aspects play a more decisive role than has been envisioned in the TA redecision method and similar approaches of TA psychotherapy that emphasise contracts, tasks of therapy and a rational approach.

\section{Project Structure and Aim}

The dissertation is based on a one-year Transactional Analytic group therapy. Using three different approaches, three different parts of TA are investigated. The areas studied were:

- Diagnosis / Client assessment (Study I). The assessment of the 10 clients in the group therapy has been made with TA diagnostics (Script Analysis). The author and two in- dependent observers have performed these analyses, on two occasions, from a Script questionnaire. The analyses have been compared in a reliability study. The aim was to examine the reliability of making diagnostic Script analyses from a Script questionnaire. 
- $\quad$ Psychotherapy Approach (Study II). Categorization and identification of TA as a psychotherapy method, where the method of investigation was a modified discourse analytic approach, combined with reliability testing. The aim was to study whether the therapy conducted was consistent with what TA as a method prescribes.

- Therapeutic alliance (Study III). The affective dimension of the therapeutic alliance, where the CCRT method and the Plan-Diagnosis method were used. The aim was to develop the TA method by investigating the affective dimension of the therapeutic alliance. These three projects do not provide the whole answer to what Transactional Analysis psychotherapy is, but the study discusses the major therapeutic areas of diagnosis, treatment and therapeutic relationship. Overall it provides a better overview of TA's content, approach and form. The overall aim of the examination of the three selected aspects has been, with relation to the theoretical concepts of TA, to improve and renew the practical understanding of the active ingredients in TA. In addition, there has been an aim to define and determine elements in TA, so as to make it a distinct and replicable method of treatment.

\section{Method}

\section{Selection}

\section{Study Materials}

The basic data collection for the three projects was based on a video recorded TA group therapy with 10 clients and the author as psychotherapist. The therapy lasted over 24 sessions during the years 1984-85, and each session lasted three hours with a half-hour break in the middle. A professional documentary filmmaker did the recording with a variable camera and a sound engineer with a microphone on a rod.

The therapy sessions were transmitted from the original professional U-matic format to the more accessible VHS format. In total there were 66 sixty-minute tapes available of the total of 75 therapy tapes. The shortfall was due to technical problems and loss of tapes (see Table 3). The project's ethical starting points have been examined and approved by the Research Ethics Committee at Lund University (2002).

A strategic selection of 13 sessions was made according to the phases in therapy, where the beginning was represented by sessions $1-8$, middle by $9-16$ and the end by $17-24$. The purpose to choose a strategic selection was to investigate whether different results could be linked to different phases of the therapy process. In each phase a random sample was then made. These sessions then became the basis for two of the studies (Study II and III) and they were recorded over to audiotapes. Based on the audiotapes the sessions were transcribed entirely to a word program
(Word) and were roughly transcribed from a transcription key (Appendix A in published article). The total transcription of the material was 813 pages.

Ten of the 13 strategically selected sessions constituted the basic data material in the studies II and III (ordinary study). These were the sessions $2,4,6,9,11,12,16,19$, 23 and 24. Of the other three sessions 5, 15 and 21 the first two formed the basis for a reliability test in Study III and the last one as a pilot study in Study II.

\section{Therapist}

The therapist was the author and no selection of therapist had been made. The therapist was at the time of the therapy, 1984-85, thirty-seven years old and since 1979 a licensed psychologist and had graduated in 1977 as a Transactional Analyst (Certified Transactional Analyst, CTA, in the psychotherapy field) authorised by ITAA, the International Transactional Analysis Association. From 1975, he was a full-time practitioner as a psychologist in private practice. At the beginning of therapy, 1984, he was recently graduated through ITAA as a supervisor and trainer in transactional analysis (Teaching and Supervising Transactional Analyst, TSTA).

The official TA training covers all directions in Transactional Analysis. The therapist had his main reference in the Redecision therapy approach in TA and was trained in the U.S. by prominent figures in this approach, Bob and Mary Goulding and Ruth McClendon.

\section{Clients}

The therapy group consisted of 10 clients. Recruitment to the group therapy was done through the client's volunteer request of therapy to a private practice in Malmo (Institute of Life Therapy - IFL). The selection of clients was based on the temporal order of registration (waiting list). A secretary managed written and verbal information about the therapy and applications to the group. Before the beginning of therapy clients were contacted by the therapist over telephone. The call was a brief check that the conditions for therapy were Ok. Concerning the conditions from a diagnostic perspective, only clients with severe disorders like schizophrenia and manic-depression would have been denied. All of the 10 clients who were first on the waiting list were accepted. Their therapy was selffunded and they had in writing consented to the therapy being recorded on video for research purposes. All of them participated for the entire process of therapy except for Janet, who completed the therapy after half the time.

Prior to the third study (Study III) a random sample was done with five clients, consisting of Amanda, Barbara, Daniel, Eric and Harriet.

\section{Description of the Client Group}

Based on a compilation of clients' social background variables (see Tables 23 and 24), one can conclude that the group has a heterogeneous profile in terms of variables such as gender, age, parenting, siblings, education, housing and employment. 
Table 3: The basic study material from the TA group therapy 1984-85.

\begin{tabular}{|c|c|c|c|c|c|c|c|c|c|}
\hline$\frac{}{\frac{}{n}}$ & $\underset{\stackrel{ \pm}{ \pm}}{\stackrel{0}{0}}$ & $\begin{array}{l}\text { ○் } \\
\stackrel{0}{\circ} \\
\stackrel{0}{\circ}\end{array}$ & 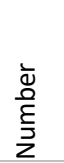 & 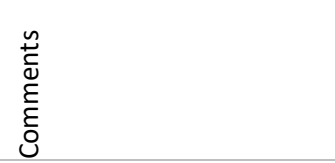 & $\begin{array}{l}\stackrel{U}{+} \\
\stackrel{0}{\sigma} \\
د\end{array}$ & $\stackrel{n}{\stackrel{n}{\prime}}$ & 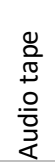 & 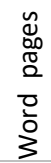 & $\begin{array}{l}\bar{d} \\
\text { ய }\end{array}$ \\
\hline 1 & 24/9-84 & $2-5$ & 4 & No. 2-5 lost & & & & & \\
\hline 2 & $3 / 10-84$ & $6-8$ & 3 & Ordinary study & Yes & Yes & Yes & 60 & Yes \\
\hline 3 & $8 / 10-84$ & $9-11$ & $2(3)$ & No 10 lost & Yes & Yes & Yes & & \\
\hline 4 & $15 / 10-84$ & $12-14$ & 3 & Ordinary study & Yes & Yes & Yes & 66 & Yes \\
\hline 5 & $22 / 10-84$ & $15-17 / 18$ & $3(4)$ & Reliability test Study III & Yes & Yes & Yes & 66 & Yes \\
\hline 6 & $29 / 10-84$ & $18-21$ & 4 & Ordinary study & Yes & Yes & Yes & 72 & Yes \\
\hline 7 & $5 / 11-84$ & $22-24$ & 3 & & Yes & Yes & Yes & & Yes \\
\hline 8 & $12 / 11-84$ & $25-27$ & 3 & & Yes & Yes & Yes & & Yes \\
\hline 9 & $19 / 11-84$ & $28-30$ & 3 & Ordinary study & Yes & Yes & Yes & 71 & Yes \\
\hline 10 & $26 / 11-84$ & 30 & 1 & No. 31-33 lost & Yes & Yes & Yes & & Yes \\
\hline 11 & $21 / 1-85$ & $34-36$ & 3 & Ordinary study & Yes & Yes & Yes & 60 & Yes \\
\hline 12 & $28 / 1-85$ & $37-39 / 40$ & 3 & Ordinary study & Yes & Yes & Yes & 78 & Yes \\
\hline 13 & $4 / 2-85$ & $40-42 / 43$ & 3 & & Yes & Yes & Yes & & \\
\hline 14 & $11 / 2-85$ & $43-45$ & 3 & & Yes & Yes & Yes & & \\
\hline 15 & $18 / 2-85$ & $46-48$ & 3 & Reliability test Study II & Yes & Yes & Yes & 64 & \\
\hline 16 & $25 / 2-85$ & $49-51$ & 3 & Ordinary study & Yes & Yes & Yes & 69 & Yes \\
\hline 17 & $4 / 3-85$ & $53-54$ & 2 & No. 52 lost & Yes & Yes & Yes & & Yes \\
\hline 18 & $11 / 3-85$ & $55-57$ & 3 & & Yes & Yes & Yes & & Yes \\
\hline 19 & $18 / 3-85$ & $58-60$ & 3 & Ordinary study & Yes & Yes & Yes & 62 & Yes \\
\hline 20 & $23 / 5-85$ & $61-63$ & 3 & & Yes & Yes & Yes & & Yes \\
\hline 21 & $1 / 4-85$ & $64-66$ & 3 & Pilot study Study II & Yes & Yes & Yes & 65 & Yes \\
\hline 22 & $15 / 4-85$ & $67-69$ & 3 & & Yes & Yes & Yes & & Yes \\
\hline 23 & $22 / 4-85$ & $70-72$ & 3 & Ordinary study & Yes & Yes & Yes & 52 & Yes \\
\hline 24 & $6 / 5-85$ & $73-75$ & 3 & Ordinary study & Yes & Yes & Yes & 28 & Yes \\
\hline
\end{tabular}

Note: Ordinary study marks the strategically selected sessions that were the basic data basis of the Studies II and III.

Summarizing the 11 variables in Tables 23 and 24, the following can be noted:

- Gender: Of the 10 clients in the group 8 are women and 2 are men.

- $\quad$ Age: Half of the group is between $30-35$ years. Three clients are younger and two are older. The median age is 34 years.

- Marital status: 6 persons are single and four are married or living together with a partner.

- Children: 6 clients have no children, while four have one or more children.

- Current housing: 9 clients live in an apartment in the city. One client is living in a house in the countryside.
- Education: 6 persons have an academic education. Of all clients nine are in human service programs. One client has a technical education (engineering)

- Employment: 7 persons are working in the caring professions. One person works as a maid, one as an arts secretary and one as a civil engineer.

- Parents: 9 clients grew up with both biological parents and one client with adoptive parents.

- Parental employment: 8 clients had mothers who were housewives. Fathers have had various nonacademic professions (9 of 10)

- Siblings: 7 clients have had 1-2 siblings while three clients have grown up without siblings.

- Childhood Environment: 7 clients have grown up in 
Table 23: Current background variables for 10 clients participating in a TA group therapy.

\begin{tabular}{|c|c|c|c|c|c|c|c|}
\hline $\begin{array}{l}\text { Client } \\
\text { no }\end{array}$ & Clients name & Age & Gender & $\begin{array}{l}\text { Marital } \\
\text { status }\end{array}$ & Children & Current housing & Education/ employment \\
\hline 1 & Agneta & $25-30$ & $\mathrm{~F}$ & Married & 1 & $\begin{array}{l}\text { House } \\
\text { Countryside }\end{array}$ & Cook/ nurse \\
\hline 2 & Barbro & $25-30$ & $\mathrm{~F}$ & Single & None & $\begin{array}{l}\text { Apartment } \\
\text { Town }\end{array}$ & University student/ maid \\
\hline 3 & Carolin & $30-35$ & $\mathrm{~F}$ & Single & None & $\begin{array}{l}\text { Apartment } \\
\text { Town }\end{array}$ & $\begin{array}{l}\text { Master of Engineering / civil } \\
\text { engineer }\end{array}$ \\
\hline 4 & Daniel & $30-35$ & $M$ & Partner & 1 & $\begin{array}{l}\text { Apartment } \\
\text { Town }\end{array}$ & Lic. Psychologist/ counsellor \\
\hline 5 & Erik & $30-35$ & $M$ & Single & None & $\begin{array}{l}\text { Apartment } \\
\text { Town }\end{array}$ & $\begin{array}{l}\text { Social worker/treatment } \\
\text { ass. }\end{array}$ \\
\hline 6 & Fanny & $20-25$ & $\mathrm{~F}$ & Single & None & $\begin{array}{l}\text { Apartment } \\
\text { Town }\end{array}$ & Nursery nurse/ Juvenile ass. \\
\hline 7 & Greta & $35-40$ & $\mathrm{~F}$ & Married & 3 & $\begin{array}{l}\text { Apartment } \\
\text { Town }\end{array}$ & Sports coach/ nurse \\
\hline 8 & Harriet & $30-35$ & $\mathrm{~F}$ & Partner & None & $\begin{array}{l}\text { Apartment } \\
\text { Town }\end{array}$ & $\begin{array}{l}\text { Social Worker/ Arts } \\
\text { secretary }\end{array}$ \\
\hline 9 & Ingegerd & $30-35$ & $\mathrm{~F}$ & Single & None & $\begin{array}{l}\text { Apartment } \\
\text { Town }\end{array}$ & $\begin{array}{l}\text { Social worker/treatment } \\
\text { ass. }\end{array}$ \\
\hline 10 & Janet & $55-60$ & $\mathrm{~F}$ & Single & 3 & $\begin{array}{l}\text { Apartment } \\
\text { Town }\end{array}$ & Social worker/ nurse \\
\hline
\end{tabular}

Table 24: Background variables related to childhood environment of 10 clients participating in a TA group therapy

\begin{tabular}{|c|c|c|c|c|c|}
\hline $\begin{array}{l}\text { Client } \\
\text { no }\end{array}$ & $\begin{array}{l}\text { Clients } \\
\text { name }\end{array}$ & $\begin{array}{l}\text { Parents/ } \\
\text { Custodians }\end{array}$ & Parents employment & Siblings & Current housing \\
\hline 1 & Agneta & $\begin{array}{l}\text { Biological } \\
\text { grandparents }\end{array}$ & Waitress and mechanic & One older sister & $\begin{array}{l}\text { House, } \\
\text { countryside }\end{array}$ \\
\hline 2 & Barbro & Biological & Housewife and caregiver & Two older sisters & $\begin{array}{l}\text { Apartment, } \\
\text { town }\end{array}$ \\
\hline 3 & Carolin & Biological & Housewife and Engineering & One older sister & House, town \\
\hline 4 & Daniel & Biological & Housewife and captain & No siblings & $\begin{array}{l}\text { House, small } \\
\text { town }\end{array}$ \\
\hline 5 & Erik & Biological & Housewife, utility workers & $\begin{array}{l}\text { Two younger brothers, one } \\
\text { older sister }\end{array}$ & $\begin{array}{l}\text { Apartment, } \\
\text { town }\end{array}$ \\
\hline 6 & Fanny & Biological & $\begin{array}{l}\text { Housewife and small } \\
\text { business owners }\end{array}$ & $\begin{array}{l}\text { One younger brother, one } \\
\text { older brother }\end{array}$ & $\begin{array}{l}\text { Apartment, } \\
\text { town }\end{array}$ \\
\hline 7 & Greta & Adoptive & Housewife and workers & No siblings & $\begin{array}{l}\text { House, small } \\
\text { town }\end{array}$ \\
\hline 8 & Harriet & Biological & $\begin{array}{l}\text { Housewife and small } \\
\text { business owners }\end{array}$ & No siblings & Houses, town \\
\hline 9 & Ingegerd & Biological & Housewife and farmer & No siblings & $\begin{array}{l}\text { House, } \\
\text { countryside }\end{array}$ \\
\hline 10 & Janet & Biological & Housewife and farmer & One older brother & $\begin{array}{l}\text { House, } \\
\text { countryside }\end{array}$ \\
\hline
\end{tabular}


a house or a villa, while 3 persons have grown up in the countryside and four in urban areas. Three clients have grown up in an apartment in a city.

The significance of the group's profile has not been investigated in this study. The clients' social conditions seem generally, however, to be "safe" but that it is not about high status or high material standard. From an individual perspective, these different background data about the clients gives a special and particular meaning for each of them in their individual therapeutic work.

From the information in the videotaped follow-up interview it appeared that six of the clients had received help with their problems by a psychiatrist or a psychologist. Four did not receive any help earlier. Three clients had been medicated for their problems, but, at the time of therapy, all clients were medication-free. All of the clients had had their problems for a long time ( $>5$ years).

At the beginning of therapy, all of the clients together with the therapist formulated therapeutic goals in the form of a treatment contract which formed the basis for the therapy work. They were evaluated at the end of therapy and in the follow-up interviews six years after the end of the therapy. All but one expressed that they had fulfilled their contracts.

\section{Instruments, codings and statistical processing}

\section{Study I}

In the study material of the first study one of Ohlsson, Björk and Johnsson (1992, pp. 178-184) designed Script questionnaire was included. This consisted of 43 questions with the possibility of open responses (Appendix A Johnsson 2011 b). The questionnaire was based on similar structures done by Berne (1972), James (1977), McCormick, (1971) and Holloway (1973). Response Data from this form were collected on two occasions from all 10 clients. The first time was before the beginning of therapy and this consisted of written answers. The second time, six years after completion of the therapy, the material consisted of individual video recorded follow-up interviews. The author instructed the clients and coordinated the collection of data on both occasions and also served as an interviewer during the video recording.

As an analytical instrument, connected to the Script questionnaire, a Script checklist (Appendix B Johnsson 2011 b) was used. This form, made up by Ohlsson, Björk and Johnsson (1992), was based on Script checklists like Berne's "Script Apparatus" (1972) and Steiner's "Script Matrix" $(1966,1975)$ and described the various major components of the Script.

In the comparison in Table 1, you can see that the Script component "Program" is not included in the form used. Experience in clinical work has shown that this component has been of minor use.
The author and two independent observers made the analysis of the Script questionnaire. Inter-assessor reliability and intra-assessor reliability was calculated statistically where the agreements in percentage and kappa values (Fleiss, 1971) were determined.

\section{Study II}

In the second study a coding key (Appendix A Johnsson 2011 a) was designed from McNeel's (1975)

categorization of the structural elements in the Redecisional approach of TA group therapy. McNeel's dissertation was primarily an effectiveness study using Shostrom's (1964) personality test, the Personal Orientation Inventory (POI) and interviews. He noted that the intensive therapy over a weekend (marathon) resulted in measurable personal changes of the clients. McNeel's secondary interest was to see what factors in the therapy led to changes in the client. It is this part that is the starting point of this study. In an article in Transactional Analysis Journal (1982), where his dissertation is summarized, McNeel writes:

One aim of this research was to establish how workshops such as these provided benefits to those involved. In pursuing this goal the researcher and an assistant studied the transcript with an eye toward discerning repeated types of questions, theoretical points of view, confrontations, instructions and techniques. Various components were consistently noted and labelled. At the end of this process the researcher had isolated 42 of these components, which were then divided into seven categories (p. 45).

McNeel's seven main categories with 42 sub-categories (components) are described in his dissertation (McNeel, 1975), in the article The Seven Components of Redecision Therapy (McNeel, 1977) and in TAJ (1982).

A revised version of McNeel's categorization was developed for this study and it was tested in the pilot study to provide the two assessors with a common understanding of the basic content of the different category definitions. In this revision process principles for the coding emerged and also classification and operationalisation of the main and sub categories. The definitions of all these categories can be found in the coding key in Appendix A in Study II Appendix A Johnsson 2011 a).

The descriptions of the main and sub categories were given TA headlines, but were defined in general psychological terms in order to be used by an independent observer, who was not trained in Transactional Analysis. The coding key was designed with the categories classified and defined in seven major categories and 42 subcategories.

The transcribed text from the 11 strategically selected sessions was put into a calculation program (Excel) simultaneously with the code key headlines for the 42 sub-categories in the form of a so-called "Pop-up menu". With access to both the transcribed text and the 42 coding categories the assessors could code the 
therapist's interventions. After a pilot study of one therapy session, the assessors developed a joint assessment of the classification of categories and a common understanding of the existing coding principles:

- The coding is based on 42 sub-categories, which are, grouped under seven main categories. The main categories serve as general headings and are not coded

- Only the therapist's statements or interventions are coded.

- Up to three of the individual narratives relevant to the categories are coded for each intervention.

- Unclear (not heard) statements are excluded from coding.

The author and an independent assessor performed the codings. Inter-assessor reliability for the main and sub categories were calculated statistically both from percentage agreement (Araujo \& Dearborn 1985), Kappa ratio (Cohen, 1960) and Odds Ratio (Viera, 2008).

\section{Study III}

In the third study the affective dimension of the alliance between therapist and client was examined. The study was carried through using the CCRT method, CORE Conflictual Relational Theme method, (Luborsky \& CritsChristoph, 1990) and Plan-Diagnosis Method (Weiss \& Sampson, 1986) - methods specifically developed within the psychodynamic therapy.

The CCRT method was applied to the transcribed therapy sessions with the aim to formulate the client's core conflictual theme (individual CCRT). In the therapy transcripts first shorter or longer sequences that were expressions of the client's spontaneous "stories" about the interaction with others, including the therapist, were identified. These stories are named Relational Episodes (RE). The REs where the client interacts with the therapist are referred to as "enactments". Based on various Rees the client's CCRT is described by identifying three components. These are the client's "Wish" (W) in relation to others, the client's expectation of the response to this request (Response from Others $=\mathrm{RO}$ ) and the client's own response to RO and his Wish (Response from Self $=$ RS). First tailor-made components were described, which are variants close to the language used by the client. They were then transformed into socalled standard categories (Barber, Crits-Christoph \& Luborsky: Expanded Standard Categories Edition 2, 1990). These include $35 \mathrm{~W}, 30 \mathrm{RO}$ and 31 RS categories. A coding sheet for each client and session was constructed, where all the CCRT data was inserted. The client's two or three most frequent combinations of W, $\mathrm{RO}$, and RS determined his individual CCRT.

The next step was to use the Plan-Diagnosis Method according to Weiss and Sampson (1986). The basis for this method, is that the client's perspective is rooted in negative experiences of encounters with significant others, which has led to the foundation of feelings of guilt, shame, fear and helplessness (= anxiety). This, in turn, has led to the client developing, as Weiss and
Sampson puts it, pathogenic expectations, which in adult life affects and limits his interaction with others. According to the authors, the client "tests" the negative expectations in the therapy situation with the hope that they will not be proved or confirmed (Confirmation). The client really has an "unconscious plan" for how his pathogenic expectations must be rebutted or refuted (Refuting)

Using this method the REs in the coding sheets, coded as interactions with the therapist (enactments), and which also corresponded to the client's individual CCRT, were examined. These were called "tests". Finally, how the therapist challenged these "tests" was coded, and in accordance with the method it was marked when he was able to confirm (= "failed") or refute (= "was successful") the clients "test".

Assessors codings in the study consistently followed the principal to first conduct an individual reading and coding of the transcribed sessions, and then jointly discuss, interpret and assess the codings up until a common consensus decision was made.

A reliability test from two separate sessions was made, by calculating the percentage of agreement in the evaluators' codings.

\section{Summary of Results}

\section{Study I}

Client Assessment in Transactional Analysis - A Study of the Reliability and Validity of the Ohlsson, Björk and Johnsson Script Questionnaire. (R. Johnsson)

Script analysis, as described in a number of categorized conflictual themes from childhood, is used by Transactional Analysts to make client assessments as a basis for treatment contracts and treatment planning.

Based on a standardized questionnaire, three experienced psychotherapists and trainers in the TA method have independently analysed the clients Scripts on two different occasions, first at the initiation of therapy and then at the follow-up interview six years after the termination of the therapy.

The results of the survey were calculated and reported by a number of correlational analyses of the similarity between assessor's analysis (inter-assessor reliability) of the clients overall script, and also by their individual scripting components on the two occasions.

Furthermore, in a comparison between the two occasions, a study was made if the initial assessments were stable over time (intra-assessor reliability).

Different assessors show (at least 2 of 3 ) with an agreement of $67 \%$ that they can define the central conflictual motives (the total Script) in the client's life situation. Focusing on the 11 primary components increases the percentage of agreement to $78 \%$. With compensation for the chance factor, reliability was assessed, according to Fleiss method (1971), to an average Kappa coefficient of 0.48 , which corresponds to a "moderate" reliability (Landis \& Koch, 1977). More 
specific Scripts (individual Script components) did not show equally high agreements. In a ranking of the Kappa ratios and percentage agreements of the Script components, the categories "primary Injunction from father", "Racket feeling", "Escape hatch", "Driver from father" and "Driver from mother" have values corresponding to a "moderate" reliability.

Conflict motifs with fixed alternatives were generally more consistent than those formulated freely by the assessors. No clear stability over time could be found. The therapist's own assessments were more consistent over time than the two independent assessors.

\section{Study II}

Transactional Analysis as Psychotherapy Method - A Discourse Analytic Study. (R. Johnsson)

The results show, that the therapist used $41.7 \%$ of the discourse space. Of the remaining space of $59.3 \%$ the 10 clients used between 3.8 and $8.3 \%$ each.

Based on a previous study of McNeel (1975), a revised categorization of seven main categories and 42 subcategories was used that were considered relevant to describe the method. Based on this model, codings were made by an assessor who was not familiar with transactional analysis (TA) and by the author, independently of each other. Reliability was compared from the assessor's codings of the subcategories. The results showed an agreement of all 42 sub-categories in an average of $33.4 \%$. A limited comparison of the seven main categories increased the agreement to an average of $46.2 \%$ (Araujo \& Dearborn 1985). The average Kappa ratio (Cohen, 1960) was calculated to 0.32 . All Odds Ratio $(\mathrm{OR})$ ratios are $>1$, which strengthens the connection between the assessors matching codings (Viera, 2008). The results indicate, according to Landis and Koch (1977) estimates of "fair" reliability.

The conclusion is that the therapy contains the components that are specific in Transactional Analysis group therapy. In a ranking of the main categories, one finds a variation in which "moderate" reliability is measured for categories "Feeling Contact" $(\mathrm{k}=0.48)$ and "Contract" $(k=0.44)$. This also applies to six of the subcategories where the techniques "Talking to parent projection" ( $\mathrm{k}=0.55)$ and "Active use of TAterminology" ( $k=0.55)$ has the highest value. The others are "Make feeling statements" ( $\mathrm{k}=0.52$ ), "Mutual negotiation" ( $k=0.47)$, "Refer to contracts" $(k=0.46)$ and "Discrepancies in body language" $(\kappa=0,44)$.

The results also show a clear variation in the frequency of the various category codings, where certain categories with a high frequency could be identified as more "TA specific". One such specific intervention with "moderate" agreement, could be distinguished, namely "Mutual negotiation".

\section{Study III}

The Affective Dimension of Alliance in Transactional Analysis Psychotherapy. (R. Johnsson \& G. Stenlund).

According to Bordin (1979), there are two aspects of the alliance, one agreement between client and therapist on therapy goals and tasks, and one special emotional or affective bond. Some therapies emphasize the first, more rational aspect of the alliance, while others emphasize the second. Freud (1912/1958) argued that the irrational, unconscious, positive transference was the strongest motive for the client's cooperation with the therapist, but later added the importance of alliance with the client's conscious and rational reality-based ego. Sterba (1934) termed this observing part "ego alliance". Greenson $(1965,1967)$ termed it "working alliance" and regarded it as more important than the emotional "therapeutic alliance". In Bordin's definition, alliance is a pan-theoretical, general umbrella term, both in relation to the transference, countertransference, the real relationship and the technology with which the characteristics, qualities and aspects of the therapy relationship can be empirically examined. According to Paul and Haugh (2008), most effect studies of the alliance after 1990 is in accordance with Bordin's conceptualisation. As Sterba and Greenson, Transactional Analysis is coming from the ego-psychological tradition. In this, usually the rational aspect is emphasized, as a contract-oriented approach is an indicative of the therapy. The aim is to reduce the time-consuming affective transference processes, and to accelerate change through a conscious and goal focused alliance with the client. Rational here is not to be understood as emotionally withdrawn. On the contrary, much of the emotional expressions of the real "normal" relationship are intense and genuine.

This study is focusing on "emotional" aspects important for the alliance between client and therapist. The client's affective relationship patterns have been identified with the help of the psychodynamically oriented CCRT method, CORE Conflictual Relationship Theme method (Luborsky and Crits-Christoph, 1990, 1998). How the therapist is responding to the client's affective messages ("test") have been estimated according to the Plan-Diagnosis method (Weiss \& Sampson, 1986).

The quantitative results show to what extent the therapist "fail" (confirm) and "manage" (refute) the clients "test". Overall, the therapist "managed" most tests $(70 \%)$, where the proportion of positive responses to Daniel's and Eric's test is higher ( $82 \%$ and $100 \%)$. compared to the therapist response to Agneta, Barbro and Harriet's test (63\%, $60 \%$ and $62 \%$ ).

These results have been complemented by a qualitative analysis of the therapeutic process in which the interpretation procedure was clarified. Overall, the 
results show that the "emotional" aspect is given more space than can be expected, based on what the TA method prescribes, where contracts and other "rational" techniques and approaches are emphasized.

\section{Discussion}

\section{Main results}

The three key therapeutic areas diagnosis / client assessment, psychotherapy methodology and therapeutic alliance have been studied with the following main results:

- Diagnosis / Client Assessment (Study I). A qualified Transactional Analysts can make an overall assessment of a client's basic conflictual themes with a "moderate" reliability. The result can be achieved by using the TA method Script Analysis, based on the primary elements of the script (Script Components) and made from a Script questionnaire. You cannot just rely on the individual Script components being assessed correctly, except for a few, which have good reliability. The nonverbal information does not appear to significantly affect the analytical results. Validity is not examined and thus the result doesn't give information about Script questionnaires or Script concept's validity.

- Psychotherapy Method (Study II). It is possible to identify what in general terms represent a TA group therapy with "fair" reliability. Two individual major categories of the seven, namely the techniques "Feeling Contact" and "Contract" had a slightly higher "moderate" reliability than the other five. This also applies to six techniques of the 42 subcategories, "Talk to the parent projection", "Active use of TA-terminology", "Make feeling statements", "Mutual negotiation", "Refer to contracts" and "Discrepancy in body language".

Only one of these interventions could be identified as "TA-specific", namely "Mutual negotiation".

- Therapeutic alliance (Study III). The "affective" aspect is given more space than can be expected, based on what the "rational" Redecisional TA method prescribes.

The results from the three studies reflect both the general and the specific nature of the TA approach, where both consistency and deviation from the therapy's expected treatment methodology is apparent. The results indicate that TA therapists can use their standard TA terminology "Script" for client assessments. The expected main elements of the TA method can be identified. The affective dimension of the therapeutic alliance was emphasized more in practical work than the TA method prescribes.

The results points to and deepens our understanding of the relationship between the theoretical conceptual descriptions, the use of empirical material and the pedagogical functional skills. By gaining a theoretical overview, categorize and empirically examine the different parts of the TA method, the results of these studies give both a more complex and more accurate picture of TAs approach, which can form the basis for further modifications and research.

\section{Methodological considerations}

All three studies have their starting point in the TA therapy that was video-filmed 25 years ago with the author as therapist. The disadvantage with such a long time perspective is that a recent development in the psychotherapy field, influencing the TA method, has not been included in the study. One such example is influences from Bucci (2008) on how to work and understand the client's Script based on its non-verbal and somatic level (Cornell, 2008). The advantage is that a clear distance to the material has occurred, which can reduce any "allegiance" problems that the author may have, in form of loyalty and trust to his psychotherapy method and therefore a desire for positive outcomes. "Allegiance" is a manifestation of systematic biases in comparisons between the effects of different psychotherapy methods. One may have a preference for one method (positive allegiance) and one can be opposed (negative allegiance). Luborsky et al. (1999) showed that the results of a therapy were in the expected direction that the effect size was higher for positive and lower for negative allegiance. The most important actions to control a positive allegiance have been the use of independent observers in all the studies (research triangulation). In study I, however, all the analysts and colleagues were linked to the TA method, although the assessor's analyses were completely independent. In Study III, the independent assessor had a positive allegiance to "alliance research", even if she wasn't linked to the TA method.

The recording was done with two professional filmmakers present, which guaranteed a good technical management. But their presence also constituted a variable with a possible group dynamic influence. This, as well as how the video recording influenced the therapist and the clients, has not been investigated.

In all of the studies the analytical method, triangulation, has been used. The dissertation in itself is an example of triangulation, both theoretically and methodologically; three different methods are used to study the different parts of TA. In Study III the methodological triangulation of quantitative and qualitative interpretive methods were used to document the clients studied. In Study II a combination of discourse analysis and statistical reliability calculations was used. In study I data triangulation, where both questionnaires (list of Script questions) and interviews, was used.

In studies II and III video material has been transcribed from audiotapes, which has given material based only on verbal printed transcripts. A transcription key has been used where auditory but not visual impressions could be shared, which limits the interpretation of process variables. In study I these visual components were used when observing the videotaped follow-up material. This was not interpreted to have any 
significant effect compared with the analysis of the written answers to the interview questions. Based on what has been learned by Tomkins (1962, 1963, 1991, 1992), the expression in the eyes is important to affective communication and attachment, and therefore a review of the video material was expected to strengthen and complement the set view of the variables. Although the assessors agreed on the nonverbal significance for the analysis, this didn't result in any significant difference. This may be because the interviews were well structured and didn't invite to any direct emotional expression.

In study II a strategic selection to study if different phenomena could be linked to different stages of the therapy process was used. The motive was to study if the distribution of the therapist's interventions shifted over time, as the clients' needs were changing. One may expect that the professional progress of the change process follow certain generally predictable steps, even if individual differences in the therapist and client (the therapeutic relationship) is essential. Berne (1961, 1972), Erskine (1973), Woollams and Brown (1978), Ohlsson, Björk and Johnson (1992), Goulding and Goulding (1979) and Hewitt (1995) have described these phases of TA therapy. It can also be found in contemporary research e.g. Prochaska and Norcross (2010). The result in the study confirmed this thinking.

\section{Reliability and validity}

Reliability and validity are concepts, which in their original definition, are designed for studies with quantitative approach, but which later have been applied in studies with qualitative approach. The dissertations naturalistic studies are basically qualitative with additional quantitative elements. The data collection in study I consisted of questionnaires, interviews and video observations. In studies II and III independent assessments of the transcribed video sessions have served as the base material. In study II, assessors used a classification of the TA categories according to McNeel (1975) as an instrument for their coding, while assessors in Study III has coded from a psychodynamically oriented categorization, according to Luborsky and Crits-Christoph (1990, 1998). The quantification has consistently been based on prespecified categories (script components, TA-therapy categories, CCRT standard categories), which systematically has been coded by different observers, been compared and statistically calculated. These quantifications of qualitative material brings with it known methodological problems, because the qualitative research method wants to find the essence and aims to provide qualitative empirical evidence, while the quantitative method is primarily looking for statistical and quantifiable results.

The study's naturalistic approach in combination with a limited number of clients partly reduces the possibility to generalize the results to other therapies. The ambition has generally not been to determine the outcome, but to qualitatively distinguish the categories that best describe the phenomena that are studied, and to determine the key categories in a TA-therapy. Using distinct statistical analysis while maintaining the authentic connection to a complex reality is a delicate balance between taking into account both the external and partly internal validity.

\section{Reliability Problems}

In study I raw data have consisted of responses from the Script interviews partly in the form of written responses, and partly in the form of observations of videotaped interviews. Three specially trained assessors carried out the assessments and interpretations, which consisted of Script Analysis. Sources of error with human beings as measuring instruments are many and create known reliability problems (Armelius \& Armelius, 1985, p. 2326). By using multiple assessors (inter-assessor reliability), making independent assessments on several occasions (test-retest reliability or intra-assessor reliability) and using assessors who are well trained and experienced Transactional Analysts, the ambition has been to increase the scientific consistency in terms of both reliability and validity.

By having the therapist leading the video interviews himself you can have a clear, confident and trusting situation created for the client. In addition, the same questionnaire is used on both occasions. The time interval between the two sessions is 6 years, which means that the result has probably been influenced by the client's maturation, development, and possibly other treatments. At the same time the client's memory of previous measurement responses have diminished, which stabilises the reliability in a classical sense. Perhaps stability is a better term than reliability.

This is not a reliability study in which the therapist is largely responsive to a specific manualised treatment procedure (adherence). The therapist's adherence to his methodology has been linked to positive outcomes by particularly Luborsky et al (1985), but his research also demonstrated that the therapist more easily was responsive to his techniques, when the client is motivated and cooperative and develops a "working alliance" with the therapist. The theoretical and operational definitions of the script and its various components are qualitative and diverse, which creates adherence problems related to the therapist's way of practicing the therapy. As it is based on clinical practice, it requires a clinical and constantly modified observation of the process. Consequently, the concepts will be less well defined to allow the inter-assessor reliability to be expressed in simple statistical terms (coefficients). The logical-deductive model has been used to quantify Script impressions, well aware of the subjective and qualitative elements of the definitions and observations. The aim has been to not let the assessors' prior understanding colour the final assessment results, but at best it will be a reliable measure of inter-subjectivity where the analysis in principle is the same, no matter who makes them. 
In Study II the therapist's adherence to his method is an important part of the result, since the therapist's interventions are connected to a categorized method. It becomes critical how "purely" the therapist can stay with the "official" school training. That said, with the risk that it will be the therapist's adherence to the method that will be studied and not the TA method. Canestri (2006) argues that there is a possibility that therapists develop, through further education, practical applications and personal experiences, "private" adaptations of the "official" method. Despite this, it may nevertheless be claimed that probably the "official" method forms the basis for any new development that can be observed and identified. In all the studies analytical data has been used to make correlational analyses of the assessors' agreements (inter-assessor reliability). Primarily, percentage agreement has been calculated, but in Study II and III Kappa coefficients has been set to compensate for the chance. In Study III, the assessors have used an individual interpretation procedure followed by a consensus discussion and a mutual agreed upon decision. The reliability of the coding has been supplemented by a simple percentage reliability assessment and with a qualitative analysis to emphasize the quantitative result.

\section{Validity Problems}

Cook and Campbell (1979) discuss problems that may occur with different types of validity. High reliability does not guarantee that the study has high relevance (validity). The validity in Study I is about to which extent the questions and answers in the interview are relevant to make an assessment of the Script, its components and its significance. The operationalisation of the theoretical definitions of the concepts are not precisely described but rooted in clinical practice. This means that the concepts validity (construct validity), i.e. how well the Script questionnaire leads to the Script concepts is complex. The content validity (content validity), how well the script questionnaire covers the different script components, has never been tested empirically, but has been assessed from face validity by different TA therapists. The interviews and assessments indicate that the "face validity" was good, since the motivation, confidence and knowledge about the interview was high among the interviewers and interviewees. The therapy room where the interviews are made and the direct contact between the therapist / interviewer and the client, may in this context be regarded as an authentic environment with good ecological validity (Shadish, Cook \& Campbell, 2002). The video observations can be assessed to see how clients react and respond to the interview questions. This on-line validation is built into the interview dialogue, and has been used in other studies such as family therapy (Gustl et al, 2007; Sundell, Hansson, Andree Lofholm et al., 2006).

In a predominantly qualitative study, it becomes important to describe how to collect and process data in a systematic way (internal validity). The Script interview in the study is compiled by the assessors and has been used in a clinical context during a 25 -year period. It can be considered relevant and reliable for its intended purpose.

Through a careful and detailed description of how this and other important parts of the research have been carried out, communicative validity (Malterud, 1998), and in the final results and changes in the Scripts, the reader is provided with good opportunities to determine how transferable this approach is to other similar situations (external validity). My assessment is that the reader is given good opportunities to determine the level of generalization.

The Script questionnaire is not standardized and there is no study in the literature in which the form has been validated against an independent standardized and statistically assured personality interview. Two effectiveness studies, McNeel (1975) and Bader (1976) have been made, where the Script changes were compared with assessments based on POI, Personal Orientation Inventory (Shostrom, 1977). Script Analysis has here been made from the various Script components, although no direct use of Script questionnaires has been reported. The results were based on measurements before and 3 months after therapy, and showed measureable changes in the clients' personality orientation, for example in selfacceptance and spontaneity.

The difficulty in the clinical research method, to use the criteria for validity that follows the positivistic science approach has been discussed. In the clinical research method, the "truth" is, to a large extent, linked to the practical consequences. A widening of the validity concept, which takes into account the therapeutic movement or process, may therefore be appropriate. Kvale (1987) and Polkinghorne (1983) have presented two validity criteria that are relevant in a clinical context, namely the communicative and pragmatic validity.

The communicative validity is about scientific reasoning where you continually reflect and logically weaves together theory and practical implications to a discourse that gives a credible and relevant impression. The different components of Script theory are tested partly internally (how they are logically linked) and partly externally (how they are related to other theories). The internal rationale has been put forward in the section about the Script and its components and the external has been examined in several studies in which TA was compared with other treatments (Goodstein, 1971; Ohlsson, 2002; Novey, 1999; Shaskan, Moran \& Moran, 1981), where Script application of TA therapy gave a positive outcome. The pragmatic validity is linked to the prolonged use of the method and an experience that it has been effective in clinical work.

Finally, it should be mentioned, that the internal validity of this study is strengthened through triangulation, where three different non-TA-related methods have been used to study different aspects of TA- therapy. 


\section{Conclusions}

\section{Discussion of Results}

By studying Transactional Analysis therapy with three different research methods, the combined results from the investigated areas (diagnosis, treatment method and therapeutic relationship) provide an overall view of the Transactional Analytical psychotherapy.

The conclusion (Study II) is that the psychotherapy under study follows what generally constitutes TA psychotherapy. Of the 42 subcategories coded, "Mutual negotiation" is clearly the most frequent one and was assessed to be a TA-specific category. It is included under the main category of "Contract". TA is consistently described as a contract therapy in which the mutual negotiation is an important ingredient in the therapeutic collaboration. The idea of contract is also referred to in the cognitive behaviour therapy (Beck, $1976,1995)$, but is not pervading the therapy and the therapist's attitude in such a profound way as in TA. Even if this TA-specific intervention is shared with other therapies it is practiced in a TA-specific way. Another common category in the study is "Specificationclarification". This category tends to be represented, more or less, in all therapies and therefore it can be assessed as a non-specific or common factor. Holmqvist (2006) and Lundh (2006) have discussed the difficulties in distinguishing theory related characteristic ingredients from common and temporary ones. Messer and Wampold (2002) and Luborsky et al (2002) showed that the differences between methods were small and that many "psychotherapy-interventions" are shared by most therapies. The TA method also has an integrated or eclectic focus, which complicates the realignment from other therapies.

Methodologically, the study demonstrated that several of the 42 categories could be deleted. In future research, such a reduction of non-relevant TA categories can function as a basis for specification and development of TA-specific elements in the theory and method.

The qualities of the therapeutic alliance are usually mentioned as an important common mechanism of effect. In study III, one can conclude, that the affective dimension of the alliance has received more space than is ascribed to the TA method. The result is interesting, because the specific design of the treatment method is less important and the focus is directed to the psychotherapist and the client. Rönnestad (2006), Sandell $(2004,2009)$ and Armelius (2002) have shown that the variance in the therapist factor is more important than the method. The therapist's relational approach is partly given through his studies of the methods literature, training and supervision, but also by the therapist's personality and personal development. There is a conflict between different therapeutic approaches that can be linked to the Lundh (2006) discussion of "relationship as technology". He concludes that the relationship as a technique always is included in therapy, but it can have different meanings. He contrasts an "empathic-validating" approach to a "steering-influencing" approach. The first attitude is focused more on the inner world of the client's by emphasizing empathy and listening, as compared to the latter method, which is more encouraging concrete behaviours and thinking. It appears that the therapist in the study has some difficulty in balancing these different approaches, where the TA technique is more in line with the steering-influencing approach, compared to the empathic-validating. The therapist applies the techniques as a strategy to push the process forward, but instead it sometimes generates setbacks and lockups in the process. In connection with the resulting conflicts, it seems that the therapist follows a general methodological factor that repairs or balances the situation and that may rather be linked to the therapist than to the method.

Based on Bordin's definition of alliance (1976) the affective part of the alliance has been focused, to contrast it to the rational part. In line with psychodynamic tradition (Luborsky, 1976) the affective level is seen as following an irrational and unconscious process, while the rational level stands for the conscious and the reality-based one. In both parts, there are expressions of feeling and thinking. The use of the PlanDiagnosis method according to Weiss and Sampson (1986) examines the client's affective "plan" to confirm his "pathological expectations". The study shows that the affective level is important in a TA therapy, even if the rational level is emphasized. To open up for the affective level, TA needs to develop both its theory and its method. TA's conceptualization is mainly rooted in a useful "methodology theory", that is close to practice. TA theory is based on the Ego state theory that focuses on the conscious ego, which leads to rational treatment content. A practical method theory is not available in psychoanalysis, but there is a consistent theory that opens up for further speculation and depth, without the direct need to be linked to clinical usefulness. Johnsson and Ohlsson (1977) described in a model four different scientific levels, from a meta-perspective of the therapy's underlying view of man and society, via theory I (psychology theory), theory II (psychotherapy theory) to practice (psychotherapy). All levels are essential, and it seems like TA needs to deepen its "psychology theory" in the future without abandoning its "psychotherapy theory". Treatment wise, knowledge of the affective level should lead to an approach where the use of techniques is put in its relational context.

In study I a "moderate" high inter-assessor reliability (78\% and $\mathrm{k}=0.48$ ) was given to client diagnoses, based on the primary components of Script Analysis. The reliability is lower than what practitioners averagely reach when diagnoses in the DSM axes are used. According to Hägglöf (2008) the reliability varies between Kappa values ( $\mathrm{k}$ ) 0.65 to 0.85 . The problem with TA diagnoses is that there is no standardization, or precision in the concepts, and because of this you don't know for sure if the Script diagnosis is valid in relation to its treatment method. TA diagnoses are not regularly tested to achieve consistency between the TA and non- 
TA practitioners, which, can be added, is often not the case in other therapies either.

On the other hand communicability to the client and usefulness is considered to be satisfactory, even if this is not confirmed in a research context. Widdowson (2010) has shown that many TA therapists use the diagnostic system DSM-IV or ICD 10 as a supplement to their TA diagnoses. ICD has a vague classification, while DSM has clear behavioural criteria and may serve as a symptomsorting instrument. In addition, TA uses many different diagnostic concepts and systems as for example analysis of Ego states, Transactions, Games, Racket feelings, Life positions and Impasses, which are not represented in other diagnostic systems.

Stewart (1996) concluded that the DSM and ICD classifications are not appropriate for TA practitioners, because of contrasting views on how to describe health problems and the tight focus on the client's symptoms. The diagnoses are usually not only following a formally structured method, but the therapist also draws his conclusions from the informal process-oriented dialogue he has with his client (Cornell, 2008). This is a dialogue in which the therapist emphasizes the observation of himself, his feelings, memories and thoughts, also known as his countertransference. (Novellino, 1984; Hargaden \& Sills, 2002). The diagnosis is then initially used in a wider sense. The psychodynamically developed OPD-2, Operationalized Psychodynamic Diagnostics (2008), has been identified as a suitable well-developed diagnostic instrument, which has become well tested in a series of reliability and validity studies.

Also PDM, the Psychodynamic Diagnostic Manual (PDM Task Force, 2006), prepared by the five major psychoanalytic organizations in collaboration with leading researchers in neuroscience and effectiveness research, emphasizes the whole by linking the subjective inner experience to the externally observable symptom. PDM is considered a good complement to DSM and ICD diagnosis. It would be important for TA practitioners to link to other systematic classifications, and pragmatically create congruence between systems. The knowledge that it is possible to describe bad health in several ways is basically fertile. It can weigh up the risk that the diagnosis has a negative effect of becoming a selffulfilling prophecy, especially for those who believe that a diagnosis always has an organic base and is a disease. Stewart and Joines (2002) have made an attempt to combine the diagnostic descriptions based on TA and DSM where they have made classifications of different personality adaptations. It has been widely spread among TA practitioners, but has not been researched closer.

There seems to be a need for an official standardized diagnostic system that can increase the reliability in the psychotherapy assessments made. There is a legal security aspect in that people can get the same assessment regardless of analysts. Different analysts cannot have different criteria. With explicit criteria it becomes easier to design and evaluate tools that facilitate problem formulating diagnosis (like estimates and structured Script interviews) and treatment followups (contract fulfilment). Explicit criteria also facilitate communication between researchers, psychotherapists and clients. Finally, a clear categorical system functions as a decision support for mutual contracts, interventions, and a well planned therapy. Hopefully, the TA method will increase its research and based on specific descriptions and evaluation measurements, you can gradually develop an alternative diagnostic classification system that builds on DSM / ICD or PDM and OPD and where TA's pragmatic concepts becomes meaningful.

TA has to meet many challenges in the future if it is going to survive as a theory and psychotherapy. There is a lot of creativity linked to observations from clinical practice. Theories are created which are directly related to an observable reality, which are useful for both therapist and client. These "methodological theories" are unique to TA and ought to be described in terms where it is fully possible to test their scientific validity. Moreover, the therapy needs to specify with which clients and which conditions it works best. The need for a constant current empirical research is crucial to complement the wide number of literature studying articles that explain and revise various TA concepts. In addition, the previous TA research could be summarized in different meta-analyses.

A strength in TA is its integrative and multi-dimensional approach, as pointed out by Prochanska and Norcross (2010). Unlike the therapies that are "faithful" to their method, this opens up for variety, flexibility and an ability to stay with the therapeutic relationship process. There is an outspoken interest in combining different directions and perspectives, and thereby develop and enriches the therapy and the therapist's skills. The additions from other directions should be supplemented together with a deepening of the theory. This can be a depth study that could lead to a simplification in clarifying TA's basic concepts in verifiable stringent theoretical postulates.

Berne (1971) wrote, "...there is only one paper to write which is called "How to Cure Patients" - that's the only paper that's worth writing if you're going to do your job". This book can hardly be written without roots in empirical academic research. It is therefore a delicate task for TA, in various ways, to ensure that the research is stimulated and maintained. Then TA's survival as a psychodynamic, integrative and relational methodology to humanistic foundation can be secured.

\section{Concluding Remarks}

By discussing the three areas of diagnosis, method and therapeutic alliance with the use of three different approaches, the following aims have been achieved:

- A better understanding of TA's strengths and weaknesses in terms of diagnosis, treatment method and therapeutic relational attitude.

- A clearer view of what is TA-specific and what is common to all psychotherapies. 
- To add and provide the benefits of academic research for practicing TA psychotherapists.

\section{References}

Araujo, R. \& Born, D. G. (1985). Calculating percentage agreement correctly but writing its Formula Incorrectly, The Behaviour Analyst, 2 (8), 207-208.

Bader, E. (1976). Redecisions in family therapy: A study of change in an intensive family therapy workshop. Ph.D. dissertation, California School of Professional Psychology.

Barber, J.P., Crits-Christoph P., \& Luborsky, L. (1990). A guide to the CCRT standard categories and their classification. I L. Luborsky \& P. Crits-Christoph (Red.), Understanding transference. The core conflictual relationship theme method (pp. 37-49). New York: Basic Books.

Berne, E. (1972). What Do You Say After You Say Hello? New York: Grove Press.

Bucci, W. (2008). The role of bodily experience in emotional organization. I F. S. Anderson (Ed.), Bodies in Treatment: The Unspoken dimension (pp. 51-76). New York: Analytic Press.

Bordin, E. S. (1979). The generalizability of the psychoanalytic concept of the working alliance. Psychotherapy: Theory, Research and Practice, 16, $252-260$.

Canestri, J. (2006). Psychoanalysis: From Practice to Theory. London: Wiley.

Cohen, J. A. (1960). A coefficient of agreement for nominal scales. Educational and Psychological Measurement, 20, 37-46.

Cornell, W. F. (2000). Transference, desire and vulnerability in body-centered psychotherapy. Energy \& Character, 30(2), 2937.

Cornell, W. F. (2008). Explorations in Transactional Analysis: The Meech Lake Papers Pleasanton, CA: TA Press.

Cook, T. D. \& Campbell, D.T. (1979). Quasi-experimentation: Design and analysis issues for field settings. Boston: HoughtonMifflin.

Fleiss, J. L. (1971). Measuring nominal scale agreement among many raters. Psychological Bulletin, Vol. 76, No. 5 pp. 378-382.

Forskningsetikkommittén (2002). Protokoll 104-2 från Forskningsetikkommittén på Lunds Universitets sammanträde 2002-03-20.(Protocol from the Research Ethical Committee at Lund University 2001-03-20)

Freud, S. (1912/1958) The dynamics of transference. I J. Strachey (Ed. \& Trans.) The standard edition of the complete works of Sigmund Freud. (Vol. 12, ss, 99-108) London: Hogarth Press.

Gaston, L. (1990). The concept of the alliance and its role in psychotherapy: Theoretical and empirical considerations. Psychotherapy, 27, $143-153$.

Goodstein, M. (1971). A comparison of Gestalt and Transactional Analysis therapies in marathons. Ph.D. dissertation, Illinois Institute of Technology.

Goulding, R. \& Goulding, M. (1976). Injunctions, Decisions and Redecisions. Transactional Analysis Journal 6 (1), 41-48.

Goulding, R. \& Goulding, M. (1979). Changing lives through Redecision Therapy. New York: Grove Press.

Greenson, R. R. (1965) The working alliance and the transference neurosis. Psychoanalysis Quarterly, 34, 155- 181.
Gustle, L-H et al. (2007). Blueprints in Sweden. Symptom load in Swedish adolescents in studies of Functional Family Therapy (FFT), Multisystemic Therapy (MST) and Multidimensional Treatment Foster Care (MTFC). Nordic journal of psychiatry.

Hargarden, H. \& Sills, C. (2002). Transactional Analysis: a relational perspective. Hove: Brunner-Routledge.

Hewitt, G. (1995) Cycles of Psychotherapy. Transactional Analysis Journal 16(3), 200-207.

Holloway, W. (1973). Clinical Transactional Analysis with Use of Life Script Questionnaire, Medina: Midwest Institute for Human Understanding.

Horvath, A.O., \& Bedi, R.P. (2002). The alliance. In J.C. Norcross (ed). Psychotherapy Relationships that Work. Oxford, England: Oxford University Press, 37-69.

Holloway, W. (1973). Shut the Escape Hatch, no IV. The monograph series of Midwest Institute for Human Understanding no I-X. Medina: Midwest Institute for Human Understanding.

Holmqvist, R, (2006). Psykologi och placebo. (Psychology and placebo) Pskologtidningen, $n r$ 10, 2006.

Hägglöf, B. (2009). Diagnostiska perspektiv inom Barn och ungdomspsykiatri: Nosologiskt

perspektiv. Föreläsning Barn och ungdomspsykiatri, Umeå universitet. (Diagnostic perspectives in Child and Adolescent Psychiatry: Nosological perspective. Lecture Child and Adolescent Psychiatry, Umeå University).

International Transactional Analysis Association (2011). Training and Exam Handbook section 7, Retrieved August 15, 2011, from http/www.itaa-net.org.

Johnsson, R. (2011). Transactional Analysis Psychotherapy Three Methods Describing a Transactional Analysis Group Therapy, Department of Psychology, Lund University, ISBN 97891-7473-185-9

Johnsson, R. (2011 a). Transactional analysis as psychotherapy method: A discourse analytic study. Retrieved from www.ijtar.org/article/view/9111

Johnsson, R. (2011 b). Client Assessment in Transactional Analysis - A Study of the Reliability and Validity of the Ohlsson, Björk and Johnsson Script Questionnaire. International Journal for Transactional Analysis Research, Vol. 2, No. 2, July 2011. Retrieved from http://www.ijtar.org/article/view/8943

Johnsson, R. \& Ohlsson, T. (1974). Två olika sätt att se på psykiska problem. (Two different ways to look at psychological problems). Arbetet, p.5.

Johnsson, R. \& Ohlsson, T. (1977). Att ta ansvar för sig självoch svara an på andra: "Ansvarsmodellen" $i$ humanistisk psykologi och psykoterapi, (To be responsible for yourself - and respond to others "The Responsibility Model" in humanistic psychology and psychotherapy), Stockholm: Wahlström \& Widstrand.

Johnsson, R., \& Stenlund, G. (2010). The affective dimension of alliance in transactional analysis psychotherapy. International Journal for Transactional Analysis Research, 1(1). Retrieved from www.ijtar.org/article/view/6144

Kvale, S. (1987). Validity in the Qualitative Research Interview. Methods, vol. 1, No. 2.

Lambert, M. J. \& Barley, D. E. (2002): Research Summary on the Therapeutic Relationship and Psychotherapy Outcome. I: Psychotherapy Relationships That Work: Therapist contributions and responsiveness to patients. New York: Oxford University Press. (pp. 17-28). 
Lambert M. J. \& Ogles B. M. (2004). The efficacy and effectiveness of psychotherapy. I: Lambert MJ (Ed.) Bergin and Garfield's handbook of psychotherapy and behaviour change. $5^{\text {th }}$ Ed. New York, Wiley, p. 139-93.

Landis, J.R. \& Koch, G.G. (1977). The measurement of observer agreement for categorical data. Biometrics 33: 159-174.

Luborsky, L. (1976). Helping alliances in psychotherapy. In J. L. Cleghorn (Ed.), Successful psychotherapy (pp.92 - 116). New York: Brunner/Mazel.

Luborsky, L., Rosenthal, R., Diguer, L., Andrusyana, T. P., Berman, J. S., Levitt, J. T., et al. (2002). The dodo bird verdict is alive and well mostly. Clinical Psychology: Science and Practice, 9(1), 2-12.

Luborsky, L., \& Crits-Christoph, P. (1990). Understanding Transference: The CORE Conflictual Relationship Theme Method. New York: Basic Books.

Luborsky L, \& Crits-Christoph P. (1998). Understanding Transference: The CORE Conflictual Relationship Theme Method, (2nd ed.) Washington, DC, American Psychological Association.

Luborsky, L., Diguer, L., Seligman, D. A., Rosenthal, R., Johnson, S., Halperin, G., Bishop, M., \& Schweizer, E. (1999). The researchers own therapeutic allegiances - A "wild card" in comparisons of treatment efficacy. Clinical Psychology: Science and Practice, 6132.Psychotherapy part I), Psykologtidningen, $n r$ 6, 19-22.

Luborsky, L., \& Crits-Christoph, P. (1990). Understanding Transference: The CORE Conflictual Relationship Theme Method. New York: Basic Books.

Lundh, L-G. (2006). Metaperspektiv på Psykoterapin del II. (Meta-perspective on Psychotherapy part II),

Psykologtidningen, $n r$ 7, 19-22.

Malterud K. (1998). Validitet. Kvalitativa metoder i medicinsk forskning. Lund: Studentlitteratur.

McCormick, P. (1971). Guide for Use Of Life Script Questionnaire in Transactional Analysis, Berkeley: Transactional Pubs.

McNeel, J. R. (1975). A study of the effects of an intensive weekend group workshop. Ph.D. dissertation, California School of Professional Psychology.

McNeel, J. R. (1977) The Seven Components of Redecision Therapy. In Barnes, G. (ed.) Transactional Analysis after Eric Berne-Teaching and Practices of Three Schools. (pp. 425-440). New York: Harper's College Press.

Novellino, M. (1984). Self-analysis of counter-transference. Transactional Analysis Journal, 14(1) 63-75.

Norcross, J. C. (2002). Empirically supported therapy relationships. In J. C. Norcross (Ed.)

Psychotherapy Relationships that Work: Therapist Contributions and Responsiveness to Patients (ss. 3-16). New York: Oxford University Press.

Norcross, J. C. \& Lambert, M. J. (2011) Evidence-based therapy relationships. In J. C. Norcross (Ed.), Psychotherapy Relationships that Work: Therapist Contributions and Responsiveness to Patients, 2nd edition (ss. 3-21). New York: Oxford University Press.

Ohlsson, T. (2001). TA i missbruksarbete - Transaktionsanalytisk psykoterapi som behandlingsmetod för drogmissbrukare $i$ miljöterapeutisk vård. (TA in Drug Abuse Work -Transactional Analysis Psychotherapy as a Treatment Method for Drug
Addicts in Therapeutic Communities), Department of Clinical Psychology, Lund University.

Ohlsson, T. (2002). Effects of transactional analysis psychotherapy in therapeutic community treatment of drug addicts. Transactional Analysis Journal 32,153-177.

Ohlsson, T., Björk, A. \& Johnsson, R. (1992)

Transaktionsanalytisk psykoterapi - TA i teori och praktik. (Transactional Analysis Psychotherapy - TA in Theory and Practice) Lund: Studentlitteratur.

Paul, S. \& Haugh, S. (2008): The therapeutic relationship: Perspectives and themes. UK: PCCS BOOKS Itd.

PDM Task Force. (2006). Psychodynamic Diagnostic Manual. Silver Spring, MD: Alliance of Psychoanalytic Organizations.

Polkinghorne, D. E. (1983). Methodology for the human sciences. Albany: SUNY Press.

Prochaska, J. O., Norcross, J. C. (2010) Systems of Psychotherapy-A Transtheoretical Analysis (7th edition) Pacific Grove, CA: Brooks \& Cole.

Rønnestad, M. H. (2006). The International Study of the Development of Psychotherapists: Implications for Supervision. Presentation, Society for Psychotherapy Research, Annual International Meeting, Edinburgh, Scotland, 21.06.2006.

Sandell, R. (2004). Teknik eller relation? Om verksamma faktorer i psykoterapi. (Techniques or Relations? About effective factors in psychotherapy), Läkartidningen, 101, 14181422.

Sandell, R. (2009). Den terapeutiska relationen- faktisk interaktion eller inre representation. (The therapeutic relation - real interaction or inner representation), Psykologtidningen, nr 9, 12-16.

Shadish, W., Cook, T., and Campbell, D. (2002). Experimental and Quasi-Experimental Designs for Generalized Causal Inference Boston: Houghton Mifflin.

Shaskan, D., Moran, W., Moran, O. M. (1981). Influence of group psychotherapy: A thirty year follow-up. Transactional Analysis Journal 11, 270-274.

Shaskan, D., Moran, W. (1986). Influence of group psychotherapy: A thirty-eight year follow-up. Transactional Analysis Journal 16, 137-138.

Shostrom, E. L. (1964) An inventory for the measurement of self-actualization. Educ. Psychol. Meas. 24, 207-218.

Steiner, C. (1966). Script and Counterscript, Transactional Analysis Bulletin 5 (18), 133-135.

Steiner, C. (1967). A Script Checklist, Transactional Analysis Bulletin 6 (22), 38-39.

Steiner, C. (1971) Games Alcoholics Play. New York: Ballentine Books.

Steiner, C. (1974). Scripts people live: transactional analysis of life scripts. New York: Grove Press.

Steiner, C. (1976). Script: Introduction. In Steiner, C. (Ed.) Beyond Games and Scripts by Eric Berne-Selections from his major writings. New York: Grove Press.

Sterba, R. F. (1934) The fate of the ego in analytic therapy. International Journal of Psychoanalysis, 115, 117- 126.

Stewart, I. \& Joines, V. (2002). Personality Adaptations: A New Guide to Human Understanding in Psychotherapy and Counselling. Nottingham: Lifespace Publishing. 
ungdomar med alvarliga beteendeproblem. (Multisystemic therapy for young people with devastating behavioural problems), Stockholm: Socialstyrelsen. ISBN/ISSN: 91-8548256-0.

Tomkins, S.S. (1962). Affect/Imagery/Consciousness. Vol. 1: The positive affects. New York: Springer.

Tomkins, S.S. (1963). Affect/Imagery/Consciousness. Vol. 2: The negative affects. New York: Springer.

Tomkins, S.S. (1991). Affect/Imagery/Consciousness. Vol. 3: The negative affects: anger and fear. New York: Springer.

Tomkins, S. S. (1992). Affect imagery consciousness: Vol. IV. Cognition: Duplication and transformation of information. New York: Springer.

Tomkins, S.S. (1995 a). The quest for primary motives. I E. V. Demos, (red) Exploring Affect. The selected writings of Silvan S. Tomkins. (pp.27-63). New York: Cambridge University Press.

Tomkins, S.S. (1995 b). Role of the specific affects. I E. V. Demos, (red) Exploring Affect. The selected writings of Silvan S. Tomkins. (pp. 68-85). New York: Cambridge University Press.

Tomkins, S.S. (1978). Script Theory: Differential magnification of Affects, I: Nebraska symposium on motivation (1979) (pp.201-233). Lincoln University of Nebraska Press.
Viera A. J. (2008). Odds Ratios and Risk Ratios: What's the difference and why does it matter?" South. Med. J. 101 (7): 730-4.

Wampold, B. E. (2001). The Great Psychotherapy Debate: Models, Methods, and Findings. New Jersey: Lawrence Erlbaum Associates.

Wampold, B. E. (2002). An examination of the bases of evidence-based interventions. School Psychology Quarterly, 17, 500-507.

Weiss, J., Sampson, H., \& the Mount Zion Psychotherapy Research Group. (1986). The Psychoanalytic Process. Theory, Clinical Observations, and Empirical Research. New York: Guilford Press.

Viera A. J. (2008). Odds ratios and risk ratios: what's the difference and why does it matter? Southern Medica Journal, 101 (7), 730-4.

Widdowson, M. (2010). Transactional Analysis: 100 Key Points. Routledge, London.

Woollams, S. \& Brown, M. (1978). Transactional Analysis. Dexter: Huron Valley Press. 